\title{
Гетероструктура для обращенного диода на основе электроосажденного в импульсном режиме наномассива оксида цинка и изготовленной методом SILAR пленки иодида меди
}

\author{
(ㄱ Н.П. Клочко, В.Р. Копач, Г.С. Хрипунов, В.Е. Корсун, В.Н. Любов, Д.О. Жадан, \\ А.Н. Отченашко, М.В. Кириченко, М.Г. Хрипунов
}

Национальный технический университет „Харьковский политехнический институт“, 61001 Харьков, Украина

E-mail: klochko.np16@gmail.com

(Получена 12 июля 2017 г. Принята к печати 16 января 2018 г.)

В качестве основы перспективной конструкции обращенного диода сформирована гетероструктура на базе массива наностержней оксида цинка и наноструктурированной пленки иодида меди. Проведено исследование влияния режимов осаждения методом SILAR и последующего иодирования пленок CuI на гладких подложках из стекла, слюды и FTO, а также на поверхности электроосажденных наноструктурированных массивов оксида цинка, на их структуру, электрические и оптические свойства. Выявлена связь изменений, наблюдаемых в структуре и свойствах этого материала, с имеющимися в нем изначально и создаваемыми в процессе иодирования точечными дефектами. Обнаружено, что причиной и условием формирования гетероструктуры обращенного диода на основе электроосажденного в импульсном режиме наномассива оксида цинка и изготовленной методом SILAR пленки иодида меди является формирование вырожденного полупроводника $p^{+}$- $\mathrm{CuI}$ путем избыточного иодирования слоев этого наноструктурированного материала через его развитую поверхность. Впервые изготовлена барьерная гетероструктура $n-\mathrm{ZnO} / p^{+}-\mathrm{CuI}$ с вольтамперной характеристикой обращенного диода, коэффициент кривизны которой $\gamma=12 \mathrm{~B}^{-1}$ подтверждает ее добротность.

DOI: $10.21883 /$ FTP.2018.09.46233.8688

\section{1. Введение}

Спектр функциональных материалов и технологий современной твердотельной микро- и наноэлектроники непрерывно расширяется [1-9]. При этом технологические подходы самоорганизации снизу-вверх (bottomup design), к которым относятся химические и электрохимические методы синтеза наноструктурированных объектов, интересны не только с точки зрения формирования резисторов, диодов, транзисторов и электронных устройств на их основе, обладающих видоизмененными параметрами или усовершенствованными характеристиками благодаря, например, использованию широкозонных полупроводниковых материалов. Не менее актуальным направлением является создание наноэлектронных приборов с особыми параметрами, в частности с характеристиками, обусловленными туннельными эффектами [7-9]. Среди них классический туннельный диод Эсаки (Esaki tunnelling diode) и его модификация обращенный диод (backward diode) выделяются такими преимуществами квантовых приборов, как высокая скорость переключения и низкое энергопотребление одновременно со способностью работать при комнатной температуре. Благодаря исключительной малоинерционности обращенных диодов, одной из наиболее перспективных областей их применения является использование в качестве детекторов очень слабых сверхвысокочастотных (СВЧ) колебаний для выпрямления малых сигналов и смешивания частот $[6,10]$. Вольт-амперной характеристике (BAX) $p-n$-перехода обращенного диода свойственны наличие крутой обратной ветви и большое сопротивление прямой ветви [4-6,10] вплоть до достижения напряжения, когда доминирует диффузионный ток неосновных носителей, обусловленный классическим механизмом прохождения электронов через барьер [11], из-за чего такой диод получил название обращенного. Функционирование туннельных диодов основано на высокой степени легирования $>10^{19} \mathrm{~cm}^{-3}$ обеих (для диода Эсаки) или одной из областей $p-n$-перехода (для обращенного диода) [10-12]. В результате в диоде Эсаки уровень Ферми лежит в пределах разрешенных зон по обе стороны $p-n$-перехода, а барьерный истощенный слой достаточно тонкий, порядка 10 нм или менее, т.е. существует вероятность межзонного туннелирования при обеих полярностях смещающего напряжения $U$. В обращенном диоде концентрация примеси в одной из областей (в $p$ - либо в $n$-области) не достигает вырождения, что приводит к выравниванию энергетических зон таким образом, что в состоянии термодинамического равновесия (при нулевом смещающем напряжении) уровень Ферми в вырожденной области попадает в разрешенную зону (располагаясь у ее края), а в невырожденной области близок к ее краю (за пределами последней) [10-13]. Благодаря этому при низких напряжениях обращенный диод выпрямляет высокочастотный переменнотоковый сигнал в квадратичном режиме, т.е. выходное напряжение пропорционально квадрату входного напряжения. Добротность обращенного диода определяется коэффициентом кривизны $\gamma$, который используется для оценки чувствительности детектора, поскольку 
величины регистрируемых сигналов (напряжение или ток) пропорциональны значению $\gamma$, определяемому, согласно $[10,12,13]$, по формуле

$$
\gamma=\left(d^{2} I / d U^{2}\right) /(d I / d U) .
$$

Среди множества современных исследований в области прозрачной и полупрозрачной микро- и наноэлектроники значительное количество работ посвящено гетероструктуре $p$-CuI $/ n-Z n O$. Во всех этих работах гетероструктуру $p$-CuI $/ n-\mathrm{ZnO}$ рассматривают как основу прозрачных и полупрозрачных ультрафиолетовых датчиков диодного типа $[14,15]$ или биполярных пленочных диодов [16-19]. Нам не удалось отыскать в литературе данных о создании обращенного диода с такой гетероструктурой. Особый интерес вызывает использование в $p$ - $\mathrm{CuI} / n-\mathrm{ZnO}$ одномерных наноструктурированных массивов оксида цинка [14,19-22], среди методов изготовления все больше внимания уделяется пригодным для широкомасштабного производства, дешевым и доступным жидкофазным методам, в том числе электроосаждению, жидкофазному химическому осаждению и его модификации - методу последовательной адсорбции и реакции ионных слоев (Successive Ionic Layer Adsorption and Reaction, SILAR) [23-27]. B работе [27] по результатам исследования кристаллической структуры, электрических и оптических свойств электроосажденных в импульсном режиме наномассивов оксида цинка и изготовленных методом SILAR пленок иодида меди нами была сформирована барьерная гетероструктура $n-\mathrm{ZnO} / p$-CuI, анализ электронных параметров которой продемонстрировал [27] ее перспективность для использования в качестве базовой приборной диодной структуры полупрозрачного детектора ближнего ультрафиолетового (УФ) излучения. В дальнейшем за счет легирования иодида меди до состояния вырождения $p^{+}$-CuI нам удалось преобразовать обычную диодную $\mathrm{BAX}$ гетероструктуры $p$ - $\mathrm{CuI} / n-\mathrm{ZnO}$ в вольт-амперную характеристику обращенного диода. Данная работа посвящена исследованию влияния режимов осаждения слоев иодида меди на различные подложки методом SILAR и последующего их иодирования на структуру, электрические и оптические свойства пленок CuI. Анализируются причины и условия формирования гетероструктуры обращенного диода $n-\mathrm{ZnO} / p^{+}-\mathrm{CuI}$ с электроосажденным наноструктурированным массивом оксида цинка.

\section{2. Методика эксперимента}

Массивы наностержней оксида цинка изготавливали, в соответствии с [27], методом импульсного электрохимического осаждения при температуре $70^{\circ} \mathrm{C}$ в трехэлектродной ячейке с неперемешиваемым водным электролитом, содержащим $0.1 \mathrm{M} \mathrm{NaNO}_{3}$ и $0.01 \mathrm{M} \mathrm{Zn}\left(\mathrm{NO}_{3}\right)_{2}$. В качестве подложек (катодов, или рабочих электродов) использовали покрытые прозрачными электропроводными слоями легированного фтором оксида олова (FTO) стеклянные пластины марки ТЕС 7 фирмы Pilkington (USA). Противоэлектродом служила платиновая спираль, а электродом сравнения - насыщенный хлорсеребряный электрод $\mathrm{Ag} / \mathrm{AgCl}$. При выращивании массивов $\mathrm{ZnO}$ на первом этапе электроосаждения создавались нанозеренные зародышевые подслои $\mathrm{ZnO}$ (seed layers) посредством подачи в течение $30 \mathrm{c}$ в том же электролите на рабочий электрод FTO постоянного потенциала -1.3 В. После этого с помощью импульсного потенциостата ПИ-50-1.1, оснащенного программатором ПР-8, для осуществления импульсного электролиза в течение 30 мин на подложки-катоды подавали прямоугольные импульсы потенциала: нижний предел катодного потенциала $U_{\text {off }}$ составлял $-0.7 \mathrm{~B}$, верхний предел $-U_{\text {оn }}=-1.3 \mathrm{~B}$ (потенциалы приведены относительно электрода сравнения $\mathrm{Ag} / \mathrm{AgCl}$ ). Рабочий цикл (duty cycle), т.е. отношение длительности импульса к сумме длительностей импульса и паузы, и частота как величина, обратная сумме длительностей импульса и паузы, составляли 0.4 и 2 Гц соответственно. Толщина $t_{\mathrm{ZnO}}$ электроосажденных массивов наностержней $\mathrm{ZnO}$ составляла $\sim 1.10$ мкм, диаметры наностержней были $\sim 200-600$ нм. Таким способом были изготовлены образцы FTO/ZnO. Снимки поверхности наноструктурированных массивов $\mathrm{ZnO}$ были выполнены методом растровой электронной микроскопии (РЭМ) с помощью сканирующего электронного микроскопа высокого разрешения SEM Tescan Mira 3 LMU.

Нанесение пленок CuI на пластины из стекла Corning 7059, на подложки из слюды мусковит, на стеклянные пластины со слоями FTO и на поверхность наноструктурированных массивов оксида цинка на FTO (на образцы FTO/ZnO) осуществляли методом SILAR. В качестве катионного прекурсора использовали водный раствор, содержавший $0.1 \mathrm{M} \mathrm{CuSO}_{4}$ и $0.1 \mathrm{M} \mathrm{Na}_{2} \mathrm{~S}_{2} \mathrm{O}_{3}$, в котором образовывался комплекс тиосульфата меди (I). Подложку погружали в катионный прекурсор на 5 c. Монослой ионов меди был адсорбирован на ее поверхности, а не адсорбированные ионы удалялись промывкой подложки в дистиллированной воде в течение $10 \mathrm{c}$. Для реакции с ионами $\mathrm{I}^{-}$подложку затем погружали на $20 \mathrm{c}$ в анионный прекурсор в виде водного раствора $0.025 \mathrm{M}$ $\mathrm{NaI}$ или $0.14 \mathrm{M} \mathrm{NaI}$. После этого слабо связанные с ней частицы и ионы удаляли промывкой в дистиллированной воде в течение 10 c. Перечисленные процедуры составляли один цикл SILAR CuI. Для получения пленок $\mathrm{CuI}$ толщиной 0.8-1.5 мкм циклы SILAR повторяли от 22 до 40 раз. Легирование слоев $\mathrm{CuI}$ на стеклянных и слюдяных поверхностях, а также образцов $\mathrm{FTO} / \mathrm{CuI}$, $\mathrm{FTO} / \mathrm{ZnO}$ и $\mathrm{FTO} / \mathrm{ZnO} / \mathrm{CuI}$ осуществляли посредством их иодирования в соответствии с [28] (solid iodination method). Для этого образцы помещали в наполовину заполненные кристаллическим иодом стеклянные бюксы и выдерживали в течение часа при температуре $25^{\circ} \mathrm{C}$, после чего извлекали, промывали и высушивали на воздухе. 
Оптические свойства электроосажденных наноструктурированных массивов $\mathrm{ZnO}$, образцов пленок иодида меди на разных подложках и композиций $\mathrm{ZnO} / \mathrm{CuI}$ в образцах $\mathrm{FTO} / \mathrm{ZnO} / \mathrm{CuI}$ исследовали с помощью спектрофотометра СФ-2000, оснащенного приставкой СФО-2000 для измерения зеркального отражения и диффузного отражения $R$. В качестве контрольных образцов при регистрации спектров оптического пропускания $T_{o}(\lambda)$ использовали соответствующие подложки. Значение максимального оптического пропускания $T_{o}^{\max }$ пленок $\mathrm{CuI}$ определяли в диапазоне длин волн $\lambda$ от 400 до 1100 нм. Оптическую ширину запрещенной зоны $E_{g}$ слоев $\mathrm{CuI}$ оценивали аналогично [27] посредством экстраполяции на ось энергий линейного участка зависимости $\left[-\ln \left(T_{o}\right) h v\right]^{2}$ от $h v$. Из-за существенного диффузного отражения пленок CuI, согласно [29,30], для более точного определения их $E_{g}$ использовали функцию Кубелки-Мунка:

$$
(1-R)^{2} /(2 R)=\beta / s,
$$

где $\beta$ - коэффициент поглощения, $s-$ коэффициент рассеяния. В соответствии с $[29,30]$ величина $E_{g}$ соответствовала точке пересечения с осью энергий $h v$ прямой, полученной экстраполяцией на $h v$ линейной части зависимости функции Кубелки-Мунка.

Степень разупорядочения структуры $\mathrm{CuI}$ оценивали по величине энергии Урбаха $E_{o}$, которую определяли, согласно [31], как котангенс угла наклона линейного участка зависимости $\ln \left[-\ln \left(T_{o}\right)\right]$ от $h v$ вблизи значения $h v=E_{g} \sim 3$ эВ. Фактор светорассеяния $\left(H_{f}\right.$, Haze factor $)$ рассчитывали в соответствии с [27] как отношение диффузного отражения $R$ к полному отражению (сумме диффузного и зеркального отражений).

Толщины $t$ пленок $\mathrm{CuI}$ определяли гравиметрически [32] в предположении, что плотность пленок соответствовала плотности массивного материала иодида

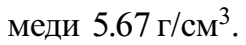

С целью анализа кристаллической структуры наноструктурированных массивов $\mathrm{ZnO}$ и пленок $\mathrm{CuI}$ исследовали рентгеновские спектры образцов (XRD), которые регистрировали с помощью дифрактометра ДРОН-4 в излучении $\operatorname{Co}_{\alpha} \quad\left(\lambda_{\text {Со } K_{\alpha}}=1.7889 \AA\right)$ или $\mathrm{Cr} K_{\alpha}\left(\lambda_{\mathrm{Cr} K_{\alpha}}=2.28976 \AA\right)$. Сканирование проводили при фокусировке по Брэггу-Брентано $(\theta-2 \theta)$. Обработка полученных рентген-дифрактограмм выполнялась с использованием программ „New_Profile v.3.4 (486)“ и „OriginPro v.7.5“. С помощью программы „Match! v.3.4.2 Build 96“ сопоставляли экспериментальные результаты с базой эталонных данных JCPDS. Оценка размера областей когерентного рассеивания $D$ (coherent scattering domain) наноструктур $\mathrm{ZnO}$ проводилась посредством анализа уширения рентгеновских дифракционных максимумов методом аппроксимаций Вильямсона-Холла аналогично [33-37]. Средний размер $D$ нанокристаллических зерен в наиболее тонких пленках $\mathrm{CuI}$ рассчитывали по уравнению Шеррера в соответствии с [27]. Для исследования текстуры электроосажденных в импульсном режиме наноструктурированных массивов оксида цинка и изготовленных методом SILAR пленок иодида меди по методу Харриса согласно [27] использовали значения интегральных интенсивностей рентгендифрактометрических пиков. Для каждого пика рассчитывали значение полюсной плотности $P(h k l)$, которая характеризует вероятность, с которой нормаль к поверхности кристаллита совпадает с нормалью к плоскости $(h k l)$, т. е. определяет количество кристаллитов, у которых плоскости $(h k l)$ параллельны поверхности образца. Полюсные плотности определяли для всех зарегистрированных рентген-дифрактометрических пиков, значения $P(h k l)>1$ приписывали осям текстуры.

С целью изучения электрических и электронных параметров образцов $\mathrm{FTO} / \mathrm{CuI}$ и $\mathrm{FTO} / \mathrm{ZnO} / \mathrm{CuI}$, в частности для исследования ВАХ гетеропереходов $n-\mathrm{ZnO} / p$ - $\mathrm{CuI}$ и $n-\mathrm{ZnO} / p^{+}-\mathrm{CuI}$, были изготовлены по аналогии с [27] полосчатые омические контакты из меди площадью $S_{c}=0.3 \mathrm{~cm}^{2}$ каждый. Процедура создания медных омических контактов была аналогична описанной нами в [27]. Во избежание шунтирования вакуумное напыление $\mathrm{Cu}$ на поверхность FTO и $\mathrm{CuI}$ образцов $\mathrm{FTO} / \mathrm{ZnO} / \mathrm{CuI}$ проводили под углом $15^{\circ}$ к их поверхности через теневую маску. Затем поверх медной металлизации наносили электропроводный клей с серебряным наполнителем „Контактол“ для создания гальванического контакта металлизации с гибкими выводами в виде медных микропроводов. Изготовленные таким способом тестовые образцы $\mathrm{Cu} / \mathrm{FTO} / \mathrm{ZnO} / \mathrm{CuI} / \mathrm{Cu}$ были использованы для измерения статических темновых BAX, которые регистрировались методом „амперметра-вольтметра“ в соответствии с [27]. Прямая полярность смещающего напряжения $U$ соответствовала отрицательному потенциалу на FTO и положительному потенциалу на CuI.

Для определения температурной зависимости удельного электросопротивления $\rho$ пленок $\mathrm{CuI}$ непосредственно после их осаждения методом SILAR на диэлектрические подложки и после иодирования использовали стандартный четырехзондовый метод с линейным расположением зондов [37] и терморегулируемым в диапазоне $290 \leq T \leq 360 \mathrm{~K}$ резистивным нагревателем. Удельное электросопротивление рассчитывали, согласно [37], по формуле

$$
\rho=\left(\pi t \delta U_{23}\right) /\left(I_{14} \ln _{2}\right),
$$

где $t$ - толщина полупроводниковой пленки; $\delta$ поправочный коэффициент, основанный на соотношении межзондового расстояния и планарных размеров пленки $\mathrm{CuI}(\pi \delta / \ln 2 \sim 4.45) ; U_{23}$ - напряжение между внутренними зондами (2 и 3$) ; I_{14}$ - ток между внешними зондами (1 и 4).

Для определения энергии активации электропроводности $\Delta E$ пленок иодида меди использовали соотношение [38]

$$
\sigma=\sigma_{0} \exp \left(-\Delta E / k_{\mathrm{B}} T\right),
$$

где $\sigma$ - удельная электропроводность $\left(\sigma=\rho^{-1}\right), \sigma_{o}$ не зависящий от $T$ предэкспоненциальный множитель, 
Таблица 1. Струкрутрные параметры и оптические свойства пленок $\mathrm{CuI}$

\begin{tabular}{|c|c|c|c|c|c|c|c|c|c|c|c|c|}
\hline \multicolumn{4}{|c|}{ Режим SILAR } & \multicolumn{6}{|c|}{ Структурные параметры } & \multicolumn{3}{|c|}{ Оптические свойства } \\
\hline \multirow{2}{*}{ Подложка } & \multirow{2}{*}{$n$} & \multirow{2}{*}{$\begin{array}{c}\text { Концентрация } \\
\text { NaI, M }\end{array}$} & \multirow{2}{*}{ Иодирование } & \multirow{2}{*}{ Фаза } & \multirow{2}{*}{$D, \mathrm{HM}$} & \multirow{2}{*}{$a, \AA$} & \multirow{2}{*}{$\varepsilon$, отн. ед. } & \multicolumn{2}{|c|}{ Текстура } & \multirow{2}{*}{$T_{o}^{\max }, \%$} & \multirow{2}{*}{$R^{\max }, \%$} & \multirow{2}{*}{$E_{g}$, эB } \\
\hline & & & & & & & & $P_{h k l}$ & $(h k l)$ & & & \\
\hline Стекло & 22 & 0.14 & - & $\gamma$-CuI PDF006-0246 & 26 & 6.04 & 0.003 & 1.8 & $(111)$ & 4 & 17 & 2.4 \\
\hline Слюда & 22 & 0.14 & - & $\gamma$-CuI PDF006-0246 & 33 & 6.05 & 0.003 & - & - & 3 & 25 & 2.5 \\
\hline Стекло & 22 & 0.025 & - & $\gamma$-CuI PDF006-0246 & 12 & 6.05 & 0.001 & - & - & 55 & 18 & 3.0 \\
\hline Стекло & 22 & 0.025 & + & $\gamma$-CuI PDF006-0246 & 20 & 6.06 & 0.001 & - & - & 54 & 20 & 3.0 \\
\hline Стекло & 30 & 0.025 & - & $\begin{array}{l}\text { Ромбоэдрическая } \\
\text { CuI PDF083-1139 }\end{array}$ & 11 & - & 0.002 & - & - & 51 & 21 & 3.0 \\
\hline Стекло & 30 & 0.025 & + & $\gamma$-CuI PDF006-0246 & 30 & 6.06 & 0.001 & 4.2 & (111) & 52 & 21 & - \\
\hline Стекло & 40 & 0.025 & - & То же & 32 & 6.05 & 0.001 & 2.4 & (111) & 3 & 31 & 2.8 \\
\hline Стекло & 40 & 0.025 & + & $\gg \gg \quad \gg \gg$ & 27 & 6.05 & 0.001 & 2.7 & (111) & 6 & 32 & 3.0 \\
\hline FTO & 30 & 0.025 & + & $\gg \gg$ & 42 & 6.06 & 0.002 & 1.6 & (111) & 74 & 22 & 2.8 \\
\hline FTO & 40 & 0.025 & + & $\gg \gg$ & 40 & 6.06 & 0.002 & 1.7 & (111) & 27 & 25 & 2.8 \\
\hline
\end{tabular}

$k_{\mathrm{B}}$ - постоянная Больцмана. Энергию активации определяли по наклону зависимости логарифма удельной электропроводности $\ln \sigma$ от $1000 / T$ к оси $1000 / T$ аналогично [35,38].

Для выяснения типа проводимости наноструктурированных массивов $\mathrm{ZnO}$ и пленок $\mathrm{CuI}$ использовали стандартный метод термозонда [39].

Расчет диодных параметров тестовых образцов $\mathrm{Cu} / \mathrm{FTO} / \mathrm{ZnO} / \mathrm{CuI} / \mathrm{Cu}$ с барьерными гетероструктурами $n-\mathrm{ZnO} / p$-CuI выполняли по методике, описанной в [27]. Для определения добротности тестовых образцов обращенных диодов проводили в соответствии c $[10,12,13]$ аналитическую обработку статических ВАХ тестовых образцов $\mathrm{Cu} / \mathrm{FTO} / \mathrm{ZnO} / \mathrm{CuI} / \mathrm{Cu}$ с барьерными гетероструктурами $n-\mathrm{ZnO} / p^{+}$-CuI путем расчета первой $(d I / d U)$ и второй $\left(d^{2} I / d U^{2}\right)$ производных и нахождения по формуле (1) коэффициента кривизны $\gamma$ при $U=0 \mathrm{~B}$.

\section{3. Экспериментальные результаты и их обсуждение}

В работе [27] нами были проведены исследования кристаллической структуры, электрических и оптических свойств электроосажденных в импульсном режиме наноструктурированных массивов оксида цинка и изготовленных методом SILAR пленок иодида меди, на основе которых удалось создать барьерную гетероструктуру $n-\mathrm{ZnO} / p$-CuI с характерной для обычных полупроводниковых диодов вольт-амперной характеристикой. Анализ $\mathrm{BAX} n-\mathrm{ZnO} / p$-CuI подтвердил ее пригодность для использования в качестве базовой приборной диодной структуры полупрозрачного детектора ближнего УФ-излучения. Представленные нами в работах $[40,41]$ результаты исследования электрических свойств и электронных параметров электроосажденных в импульсном режиме массивов наностержней $\mathrm{ZnO}$ выявили, что концентрация нескомпенсированной ионизированной донорной примеси $N_{d}$ в них находится в интервале от $2.4 \cdot 10^{14}$ при размере областей когерентного рассеяния $D \sim 30-50 \mathrm{нм}$ до $N_{d} \sim 5.6 \cdot 10^{17} \mathrm{~cm}^{-3}$ при $D \sim 40-70$ нм. Удельное сопротивление $\mathrm{ZnO}$ увеличивается в интервале $10^{5}-10^{8} \mathrm{OM} \cdot$ см с уменьшением размеров $D$ от 70 до $30 \mathrm{Hм}$, что связано с формированием барьеров Шоттки на границах областей когерентного рассеяния и на поверхности наноструктурированных массивов этого материала. Согласно [42,43], значения $N_{d} \sim 10^{16} \mathrm{~cm}^{-3}$ являются типичными для номинально не легированного $\mathrm{ZnO}$ с характерным $n$-типом проводимости, обусловленным мелкими донорными дефектами в виде вакансий кислорода $\mathrm{V}_{\mathrm{O}}$ и межузельного цинка $\mathrm{Zn}_{i}$. Поэтому очевидным способом формирования обращенных диодов на основе наноструктурированных электроосажденных массивов оксида цинка и пленок иодида меди должно было стать создание сильно легированных, вплоть до вырождения, слоев $p^{+}$-CuI.

Первым использованным нами подходом к формированию пленок $p^{+}$-CuI было повышение концентрации раствора анионного прекурсора при осаждении пленок иодида меди методом SILAR от $0.025 \mathrm{M}$ NaI до $0.14 \mathrm{M}$ $\mathrm{NaI}$. На рис. 1 показаны рентгеновские дифрактограммы и приведены результаты оптических исследований пленок $\mathrm{CuI}$ толщиной $~ 1.5$ мкм, осажденных на подложки из стекла и слюды за 22 цикла SILAR при использовании в качестве анионного прекурсора водного раствора $0.14 \mathrm{M} \mathrm{NaI}$. Можно видеть, что независимо от материала подложки пленки $\mathrm{CuI}$ однофазные, поликристаллические и имеют кубическую структуру маршита (цинковой обманки, $\gamma$-CuI, JCPDS PDF\#006-0246). Однако полученные слои иодида меди имели наряду с малыми областями когерентного рассеяния $D \sim 30$ нм значительные микронапряжения $\varepsilon \sim 0.003$ отн. ед. (табл. 1). Аксиальная текстура (111) пленок иодида меди на стекле не была совершенной (для слоя $\mathrm{CuI}$ на слюде еe не удалось проанализировать из-за совпадения дифракционного пика (111) с пиками подложки). Как видно из рис. 1 и табл. 1, искажения кристаллических решеток пленок иодида меди сказались на оптических свойствах 

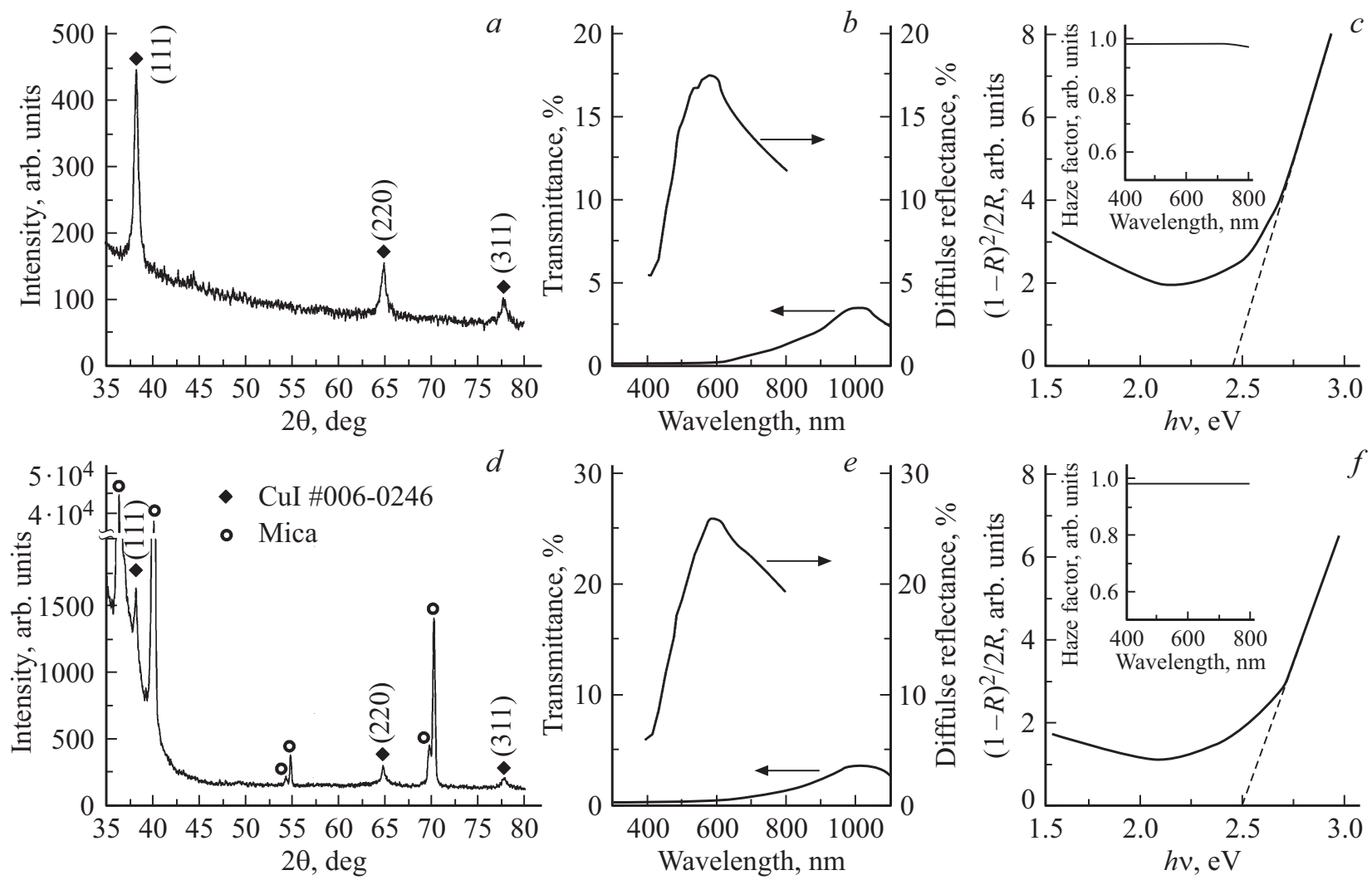

Рис. 1. Рентгеновские дифрактограммы (излучение анода $\left.\operatorname{Cr} K_{\alpha}\right)(a, d)$ и результаты оптических исследований $(b, c, e, f)$ пленок $\mathrm{CuI}$ толщиной $\sim 1.5$ мкм, осажденных на подложки из стекла $(a, b, c)$ и слюды $(d, e, f)$ за 22 цикла SILAR при использовании в качестве анионного прекурсора водного раствора $0.14 \mathrm{M} \mathrm{NaI.}$
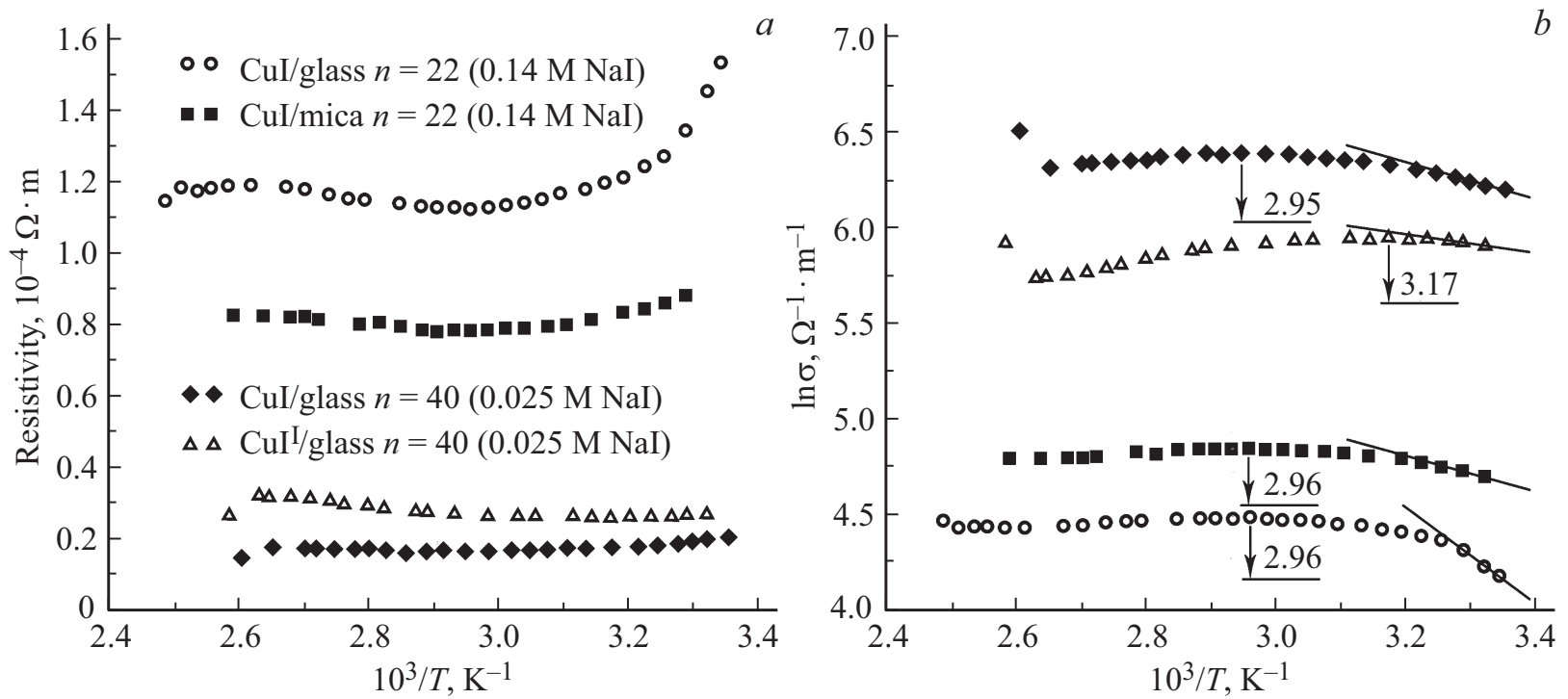

Рис. 2. Температурные зависимости удельного электросопротивления $\rho(a)$ и логарифма удельной электропроводности $\ln \sigma(b)$ для пленок CuI толщиной $\sim 1.5$ мкм, осажденных методом SILAR на подложки из стекла и слюды при использовании анионных прекурсоров $0.025 \mathrm{M} \mathrm{NaI}$ или $0.14 \mathrm{M} \mathrm{NaI.} \mathrm{(Индекс}{ }^{\mathrm{I}}$ означает последующее иодирование.)

этого материала, а именно на почти полной непрозрачности $\left(T_{o}^{\max } \sim 3-4 \%\right)$, на значительном диффузном отражении $\left(R^{\max }\right.$ до $\left.17-25 \%\right)$, сильном рассеянии света $\left(H_{f}\right.$ на уровне 0.98 отн.ед.), очень больших энергиях
Урбаха и связанных с ними заниженных величинах ширины запрещенной зоны $\left(E_{g} \sim 2.4-2.5\right.$ эВ по сравнению c $E_{g}=2.95-3.10$ эВ для массивного материала $\mathrm{CuI}$, согласно [44]). Как можно видеть на рис. 2, a, удель- 
ное электросопротивление этих пленок было низким, $\sim 1 \cdot 10^{-4} \mathrm{OM} \cdot \mathrm{M}$, т.е. того же порядка величины, что и у вырожденных полупроводниковых пленок иодида меди, представленных в работе [45]. Вместе с тем показанные на рис. 2, $a$ зависимости удельного электросопротивления $\rho$ пленок $\mathrm{CuI}$ от температуры являются характерными для полупроводников, поскольку с ростом $T$ сопротивление уменьшается, хотя и незначительно. Измерения методом термозонда подтвердили $p$-тип проводимости этих пленок. На рис. 2, $a$ показано также, что изготовленные методом SILAR с использованием концентрированного анионного прекурсора $(0.14 \mathrm{M}$ $\mathrm{NaI})$ пленки $\mathrm{CuI}$ характеризуются более высокими $\rho$ по сравнению со значениями для слоев иодида меди, полученных с применением разбавленного анионного прекурсора (0.025 M NaI). Электрические свойства хорошо согласуются с несовершенством структуры и с особенностями оптических свойств пленок, полученных методом SILAR с использованием $0.14 \mathrm{M} \mathrm{NaI}$, и, вероятно, объясняются повышенным рассеянием носителей заряда в объеме зерен и на зернограничной поверхности. Значения энергии активации электропроводности $\Delta E$ этих пленок при температурах вблизи комнатной, определенные согласно [38] с помощью уравнения (4) и графических зависимостей на рис. $2, b$, составили $\Delta E \approx 0.08$ и $\Delta E \approx 0.09$ эВ для пленок $\mathrm{CuI}$, осажденных на подложки из слюды и стекла соответственно. В соответствии с $[45,46]$ такие $\Delta E$ являются свидетельством наличия в них мелких акцепторных уровней преимущественно в виде вакансий меди $V_{\mathrm{Cu}}$, которые обеспечивают высокую электропроводность иодида меди за счет формирования свободных носителей заряда $h^{+}$по приведенной в [28] схеме: $V_{\mathrm{Cu}} \rightarrow V_{\mathrm{Cu}}^{-}+h^{+}$. Все изготовленные нами методом SILAR пленки CUI в отраженном свете выглядели желтоватыми, что объясняется наличием центров окрашивания. Согласно $[28,46]$, ими могут быть либо глубокие уровни, связанные с вакансиями иода $V_{\mathrm{I}}[46]$, либо сформированные из вакансий меди $V_{\mathrm{Cu}}$ широкие акцепторные зоны внутри запрещенной зоны CuI, существующие в этом материале при дефиците меди на уровне $0.5 \%$ [28].

Так как первый реализованный нами подход к изготовлению пленок $p^{+}$-CuI за счет использования концентрированного анионного прекурсора 0.14 M NaI оказался неэффективным, был предпринят технологический прием последующего иодирования слоев $\mathrm{CuI}$, которые были осаждены методом SILAR с использованием разбавленного анионного прекурсора (0.025 M NaI). Предполагалось, что таким способом удастся заполнить вакансии иода $V_{\mathrm{I}}$ и сформировать новые мелкие акцепторные уровни в виде антиструктурных дефектов $I_{\mathrm{Cu}}$ и межузельного иода $\mathrm{I}_{i}$. Согласно $[28,46]$, вакансии иода $V_{\mathrm{I}}$ образуют глубокие примесные центры донорного типа, способные компенсировать $V_{\mathrm{Cu}}$, и таким образом приводить к снижению концентрации в $\mathrm{CuI}$ свободных носителей заряда (дырок) $n_{h}$, что проявляется в повышенных $\rho$. По аналогии с $[44,45]$ было решено за счет обогащения пленок $\mathrm{CuI}$ иодом увеличить $n_{h}$ за счет заполнения
$V_{\mathrm{I}}$ и создания $\mathrm{I}_{\mathrm{Cu}}$ и $\mathrm{I}_{i}$ вплоть до вырождения, т.е. до формирования $p^{+}$-CuI.

На рис. 3 представлены рентгеновские дифрактограммы и результаты анализа оптических свойств осажденных на стеклянные подложки за разное количество циклов $n$ режима SILAR с использованием разбавленного анионного прекурсора $(0.025 \mathrm{M} \mathrm{NaI})$ пленок $\mathrm{CuI}$ толщиной $0.8-1.5$ мкм до и после их иодирования. Как видно из дифрактограмм на рис. 3 и из приведенных в табл. 1 результатов анализа структуры, по мере увеличения количества циклов SILAR, т. е. с ростом толщины пленок $\mathrm{CUI}$ от 0.8 до 1.5 мкм, их структура усовершенствуется, о чем свидетельствуют возрастание числа пиков на рентгеновских дифрактограммах и укрупнение областей когерентного рассеяния $D$ от 12 до 32 нм. Все пленки однофазные и, как правило, имеют кубическую структуру маршита (цинковой обманки, $\gamma$-CuI, JCPDS PDF\#0060246), хотя зарегистрировано также формирование менее стабильной при комнатной температуре ромбоэдрической модификации $\mathrm{CuI}$ (PDF\#083-1139) (рис. 3, табл. 1). Изготовленные с использованием разбавленного анионного прекурсора пленки $\gamma$-CuI характеризуются небольшими микронапряжениями ( $\varepsilon \sim 0.001$ отн. ед.) и текстурой в направлении 〈111〉, которая, согласно [28], свойственна для данного материала и вызвана влиянием энергии на стабильность фронта роста слоев иодида меди. Как показывает представленный на рис. 3 анализ оптических свойств слоев иодида меди, изготовленных методом SILAR с использованием $0.025 \mathrm{M} \mathrm{NaI}$, их ширина запрещенной зоны $E_{g} \sim 2.8-3.0$ эВ соответствует, согласно [44], характерной для CuI, а энергия Урбаха понижена, что является свидетельством более совершенной структуры пленок. Прозрачность пленок иодида меди, осажденных при использовании разбавленного анионного прекурсора, закономерно снижается с ростом толщины CUI по мере увеличения числа циклов SILAR. Отражение от таких пленок $\mathrm{CuI}$ преимущественно диффузное, $R^{\max }$ достигает $18-32 \%$, фактор светорассеяния $H_{f}$ большой, на уровне 0.95 отн. ед. Измерения методом термозонда, а также анализ температурных зависимостей удельного сопротивления (рис. 2,a) выявили, что эти пленки $\mathrm{CuI}$ являются полупроводниками $p$-типа, причем их удельное сопротивление очень низкое $\rho \sim 2 \cdot 10^{-5}$ Ом $\cdot$ м, оно впятеро меньше, чем у пленок, изготовленных при использовании концентрированного анионного прекурсора. Значение энергии активации электропроводности $\Delta E$ при температурах вблизи комнатной для пленок CuI, изготовленных методом SILAR при использовании разбавленного анионного прекурсора на стеклянной подложке, определенное согласно [38], с помощью уравнения (4) и графической зависимости на рис. $2, b, \Delta E \approx 0.08$ эВ, что в соответствии с работами $[45,46]$ является свидетельством наличия в полупроводнике мелких акцепторных уровней, обеспечивающих высокую электропроводность иодида меди, преимущественно в виде вакансий меди $V_{\mathrm{Cu}}$. Желтая окраска пленки, вероятно, может быть объяснена, в соответствии с $[28,46]$, наличием внутри запрещенной 

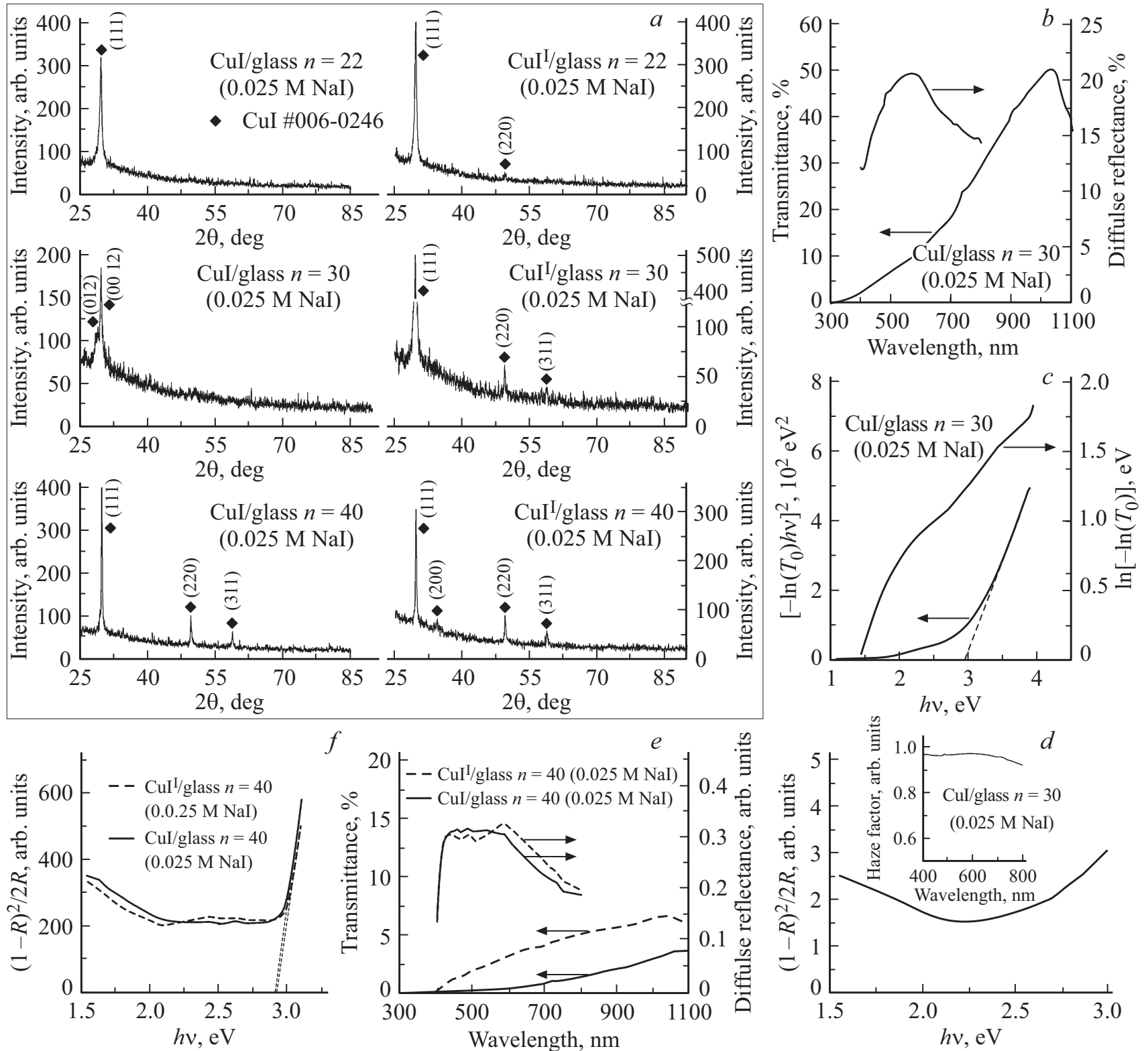

Рис. 3. Рентгеновские дифрактограммы (излучение анода Со $\left.K_{\alpha}\right)(a)$ и результаты оптических исследований $(b, c, d, e, f)$ пленок $\mathrm{CuI}$, осажденных на подложки из стекла за $n$ циклов SILAR при использовании в качестве анионного прекурсора водного раствора 0.025 M NaI. (Индекс ${ }^{\mathrm{I}}$ означает последующее иодирование.)

зоны CuI глубоких уровней, связанных с вакансиями иода $V_{\mathrm{I}}$, и широкой акцепторной зоны, образованной вакансиями меди $V_{\mathrm{Cu}}$.

Анализ структурных параметров и оптических свойств иодированных пленок $\mathrm{CuI}$, выращенных на аморфных стеклянных подложках и на поверхности поликристаллических пленок FTO (рис. 3,4, табл. 1), показал, что стадия иодирования обеспечивает перекристаллизацию пленок с увеличением размера зерен, а в ряде случаев - и с превращением нестабильной ромбоэдрической фазы $\mathrm{CuI}$ в стабильную $\gamma$-CuI. Иодированные пленки CuI, осажденные на стекле, слюде или FTO, теряют желтую окраску. Прозрачность пленок в результате иодирования повышается, хотя и незначительно, вероятно, вследствие их обесцвечивания. Ширина запрещенной зоны $E_{g}$ после иодирования значительных изменений не претерпевает (как правило, $E_{g} \approx 3.0$ эВ для иодированных пленок на стекле; $E_{g} \approx 2.8$ эВ для иодированных пленок на FTO). Как видно на рис. 2, $a$, электросопротивление в результате иодирования слоев $\mathrm{CuI}$ возрастает незначительно, в то же время форма температурной зависимости $\rho_{\text {СuI }}$ в результате иодирования пленки иодида меди изменяется существенно. Поскольку, согласно $[47,48]$ подвижность носителей увеличивается и максимум кривой $\ln \sigma(1000 / T)$ смещается в сторону низких температур со снижением содержания примеси, по изменению положения максимума на зависимости $\ln \sigma$ от $1000 / T$ на рис. $2, b$ можно заключить 

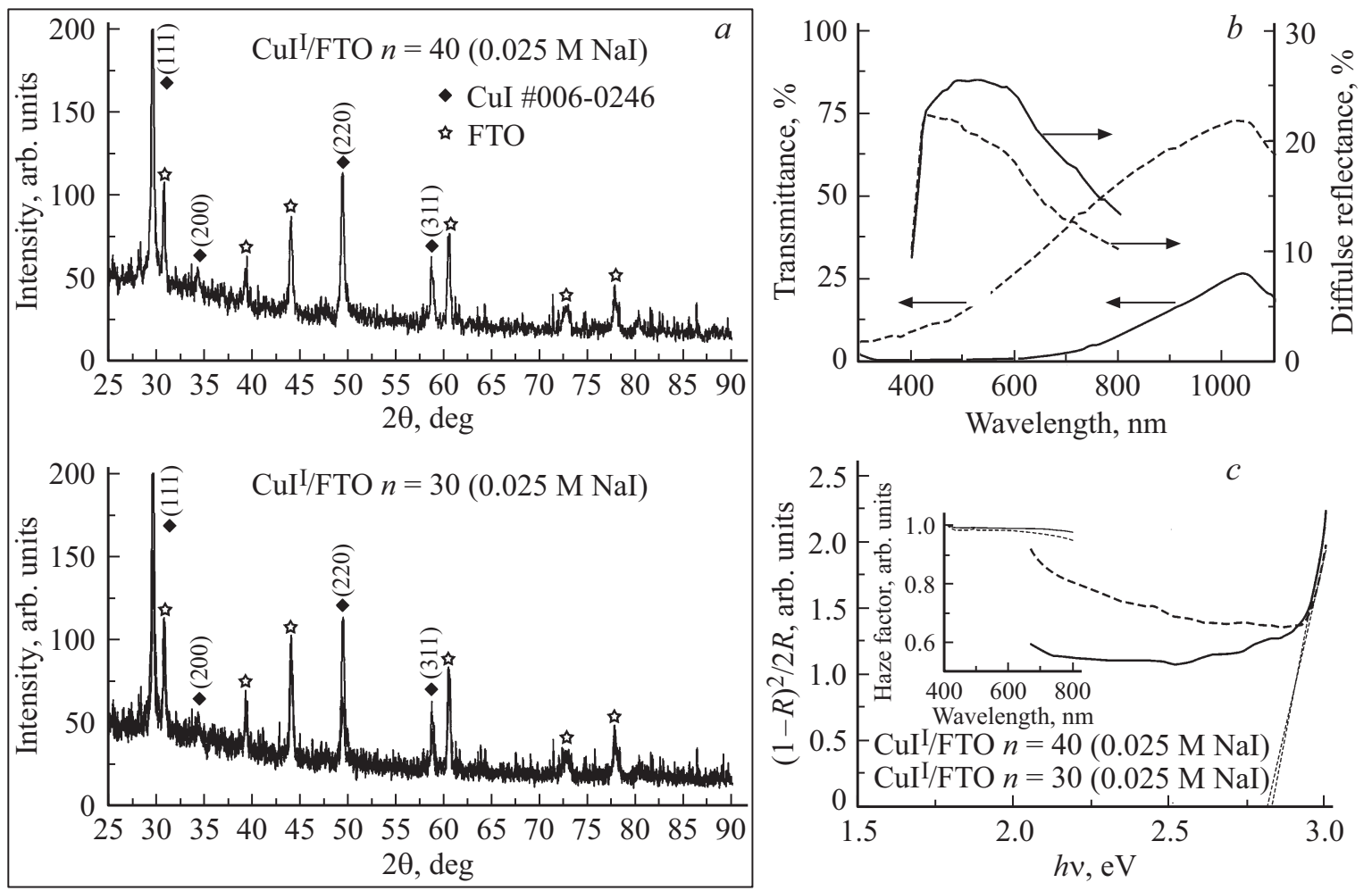

Pис. 4. Рентгеновские дифрактограммы (излучение анода Сo $\left.K_{\alpha}\right)(a)$ и результаты оптических исследований $(b, c)$ пленок СuI, осажденных на подложки FTO за $\mathrm{n}$ циклов SILAR при использовании в качестве анионного прекурсора водного раствора $0.025 \mathrm{M}$ NaI. (Индекс ${ }^{\mathrm{I}}$ означает последующее иодирование.)

об увеличении подвижности дырок в результате иодирования. Обесцвечивание пленок $\mathrm{CuI}$ после их иодирования, а также возрастание $\rho$ могут быть объяснены в соответствии с [28], как следствие сужения акцепторной зоны, обусловленной $V_{\mathrm{Cu}}$. Значения энергии активации электропроводности $\Delta E$ иодированных пленок при температурах вблизи комнатной, определенные для них согласно [38], с помощью уравнения (4) и графических зависимостей на рис. $2, b$, составили $\Delta E \sim 0.04$ эВ.
На рис. 5 показаны рентгеновские дифрактограммы образцов $\mathrm{FTO} / \mathrm{ZnO} / \mathrm{CuI}$ с электроосажденными в импульсном режиме наноструктурированными массивами $\mathrm{ZnO}$ и нанесенными на их поверхность методом SILAR (30 или 40 циклов) при использовании разбавленного анионного прекурсора $0.025 \mathrm{M} \mathrm{NaI}$ слоями $\mathrm{CuI}$ до и после их иодирования. На вставке к рис. 5, $a$ приведен выполненный с помощью РЭМ высокого разрешения снимок поверхности наноструктурированного массива $\mathrm{ZnO}$.

Таблица 2. Структурные параметры пленок CuI, осажденных на поверхность наноструктурированных массивов ZnO методом SILAR за число циклов $n$ при использовании анионного прекурсора $0.025 \mathrm{M} \mathrm{NaI}$ до и после их иодирования

\begin{tabular}{|c|c|c|c|c|c|c|c|c|c|}
\hline \multirow{3}{*}{ Образец } & \multicolumn{2}{|c|}{ Режим SILAR } & \multicolumn{7}{|c|}{ Структурные параметры } \\
\hline & \multirow{2}{*}{$n$} & \multirow{2}{*}{ Иодирование } & \multirow{2}{*}{ Фаза } & \multirow{2}{*}{$D, \mathrm{Hм}$} & \multirow{2}{*}{$a, \AA$} & \multirow{2}{*}{$c, \AA$} & \multirow{2}{*}{$\varepsilon$, отн. ед. } & \multicolumn{2}{|c|}{ Текстура } \\
\hline & & & & & & & & $P_{h k l}$ & $(h k l)$ \\
\hline FTO/ZnO & - & - & ZnO PDF 036-1451 & 59 & 3.26 & 5.21 & 0.002 & 3.5 & $(002)$ \\
\hline \multirow{2}{*}{$\mathrm{FTO} / \mathrm{ZnO} / \mathrm{CuI}$} & - & - & То же & 61 & 3.26 & 5.21 & 0.002 & 3.9 & $(002)$ \\
\hline & 30 & - & $\gamma$-CuI PDF006-0246 & 54 & 6.05 & - & 0.002 & 2.5 & $(200)$ \\
\hline \multirow{2}{*}{$\mathrm{FTO} / \mathrm{ZnO} / \mathrm{CuI}^{\mathrm{I}}$} & - & \multirow{2}{*}{+} & ZnO PDF 036-1451 & 66 & 3.26 & 5.21 & 0.002 & 3.0 & $(002)$ \\
\hline & 30 & & $\gamma$-CuI PDF006-0246 & 57 & 6.06 & - & 0.001 & 2.8 & $(200)$ \\
\hline \multirow{2}{*}{$\mathrm{FTO} / \mathrm{ZnO} / \mathrm{CuI}{ }^{\mathrm{I}}$} & - & \multirow{2}{*}{+} & ZnO PDF 036-1451 & 46 & 3.26 & 5.21 & 0.001 & 3.0 & $(002)$ \\
\hline & 40 & & $\gamma$-CuI PDF006-0246 & 35 & 6.06 & - & 0.002 & 1.5 & (111) \\
\hline
\end{tabular}



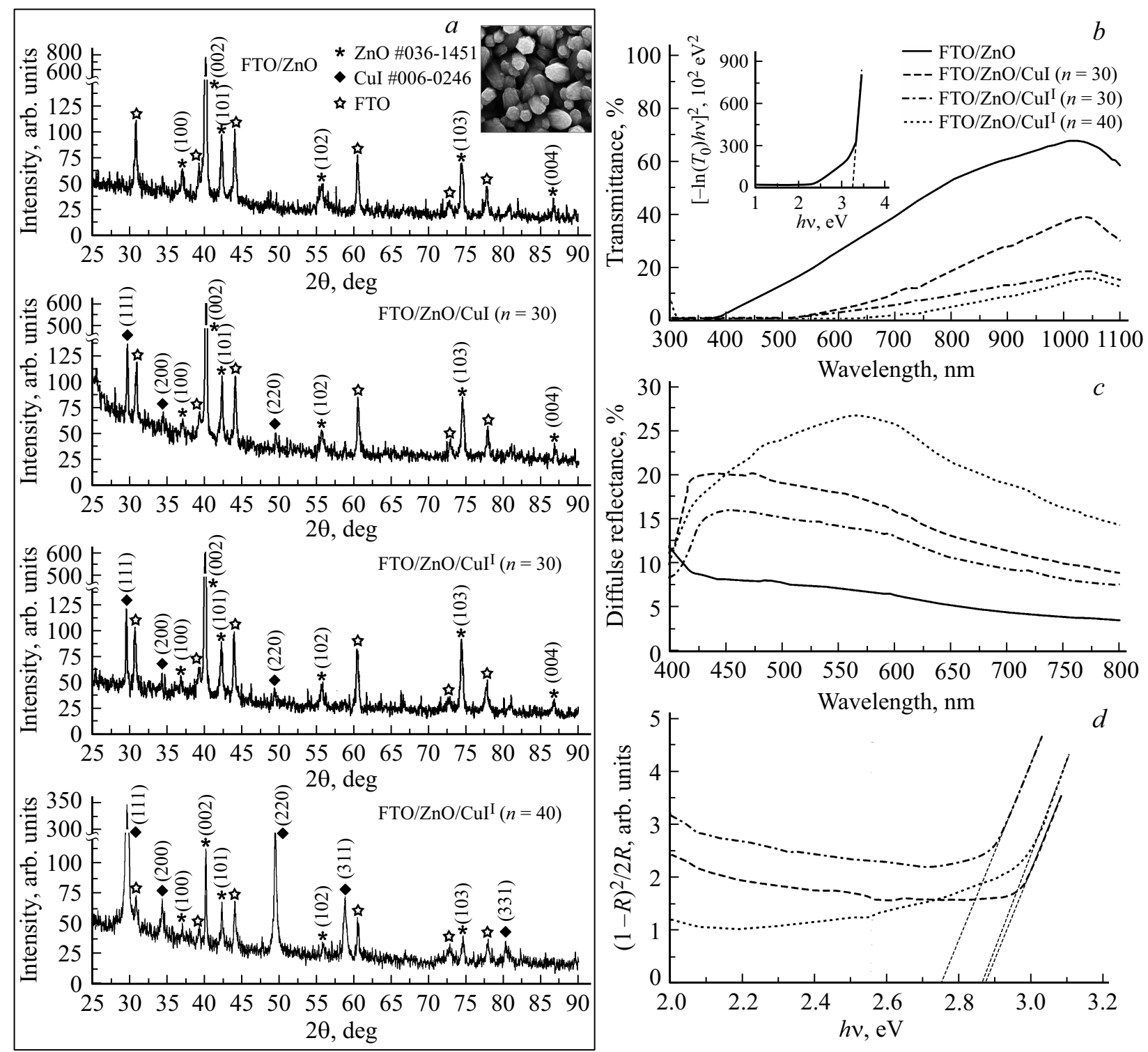

Рис. 5. Рентгеновские дифрактограммы (излучение анода Со $\left.K_{\alpha}\right)(a)$ и результаты оптических исследований $(b, c, d)$ образцов $\mathrm{FTO} / \mathrm{ZnO} / \mathrm{CuI}$ с пленками $\mathrm{CuI}$, осажденными на поверхность электроосажденных наноструктурированных массивов $\mathrm{ZnO}$ за $\mathrm{n}$ циклов SILAR при использовании в качестве анионного прекурсора водного раствора $0.025 \mathrm{M} \mathrm{NaI}$. (Индекс ${ }^{\mathrm{I}}$ означает последующее иодирование.) Вставка $(a)$ - РЭМ-изображение поверхности наноструктурированного массива $\mathrm{ZnO}$.

Сопоставление положения пиков $\mathrm{ZnO}$ на рентгеновских дифрактограммах на рис. 5, $a$ позволяет заключить, что стадии осаждения пленок $\mathrm{CuI}$ и иодирования образцов $\mathrm{FTO} / \mathrm{ZnO} / \mathrm{CuI}$ не оказывали существенного влияния на структуру ZnO. В частности, иодирование не приводило к образованию твердого раствора $\mathrm{ZnO}: \mathrm{I}$, иначе, в соответствии с [49], мы наблюдали бы искажение параметров кристаллической решетки оксида цинка в виде сдвига дифракционных пиков $\mathrm{ZnO}$ в сторону меньших углов $\theta$. Приведенные в табл. 2 результаты структурного анализа образцов $\mathrm{FTO} / \mathrm{ZnO} / \mathrm{CuI}$ до и после иодирования обнаружили, что размер $D$ областей когерентного рассеяния во

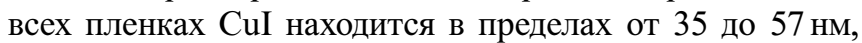
микронапряжения составляют $\varepsilon \approx 0.001-0.002$ отн. ед., направление текстуры по мере роста толщины пленки и в результате иодирования изменяется от $\langle 100\rangle$ до $\langle 111\rangle$. Анализ оптических свойств образца FTO/ZnO, а также образца $\mathrm{FTO} / \mathrm{ZnO} / \mathrm{CuI}$ до и после иодирования выявил закономерное снижение прозрачности $\mathrm{FTO} / \mathrm{ZnO} / \mathrm{CuI}$ до иодирования по мере наращивания толщины иодида меди. Вместе с тем к уменьшению прозрачности приводила также и стадия иодирования образцов $\mathrm{FTO} / \mathrm{ZnO} / \mathrm{CuI}$ (рис. 5, $b$ ), помимо этого, после иодирования наблюдалось сужению запрещенной зоны $\mathrm{CuI}$ (рис. 5,d). На вставке к рис. 5,b показана типичная для ZnO ширина запрещенной зоны $E_{g} \sim 3.3$ эВ, полученная при аналитической обработке данных оптических исследований образца $\mathrm{FTO} / \mathrm{ZnO}$. Как видно на рис. 5,c, образец 

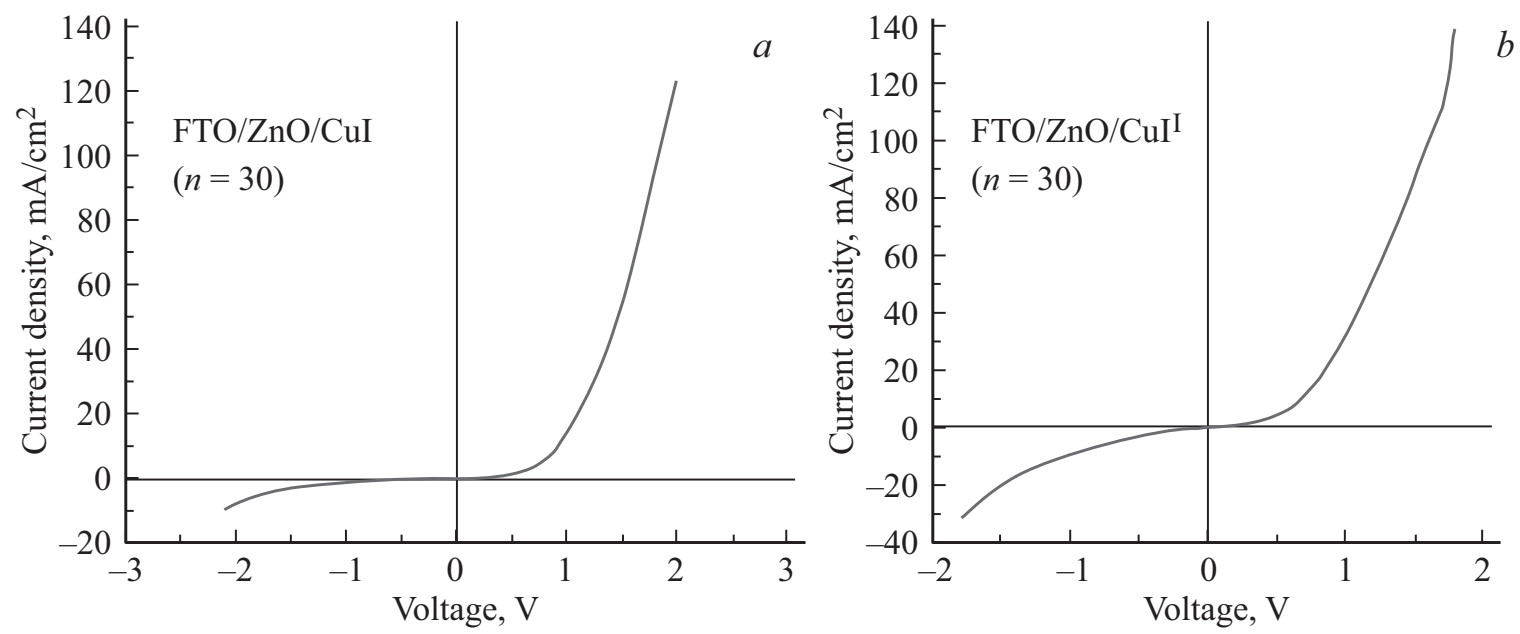

Voltage, $\mathrm{V}$

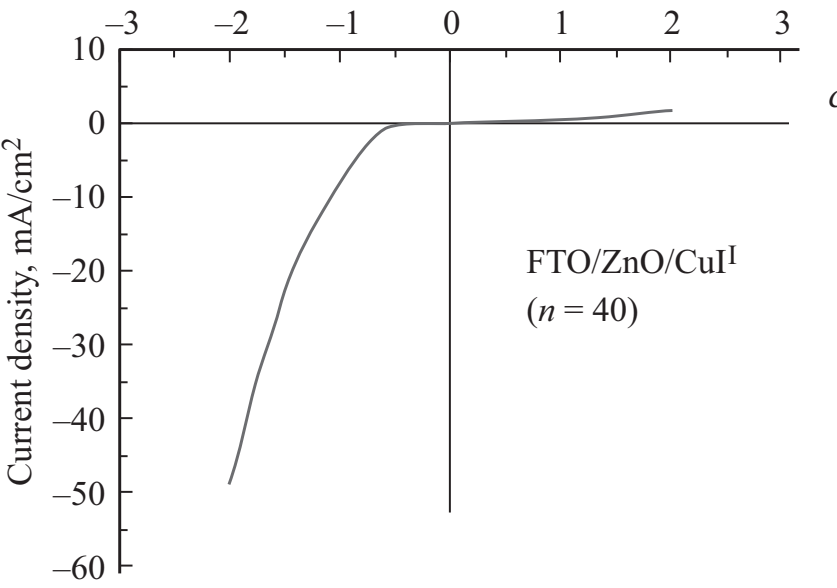

Рис. 6. Темновые BAX тестовых образцов $\mathrm{Cu} / \mathrm{FTO} / \mathrm{ZnO} / \mathrm{CuI} / \mathrm{Cu}$ с пленками CuI, нанесенными на поверхность электроосажденных наноструктурированных массивов $\mathrm{ZnO}$ за $\mathrm{n}$ циклов SILAR при использовании в качестве анионного прекурсора водного раствора $0.025 \mathrm{M}$ NaI. (Индекс ${ }^{\mathrm{I}}$ означает последующее иодирование).

FTO/ZnO/CuI со слоем CuI в 1.5 мкм (40 циклов SILAR) имел очень большое диффузное отражение $R^{\max } \sim 27 \%$. Визуальный анализ показал, что при толщине $\mathrm{CuI}$ в 1 мкм (30 циклов SILAR) образец FTO/ZnO/CuI после иодирования обесцвечивался аналогично тому, как это наблюдалось для пленок иодида меди на гладких подложках из стекла, слюды или FTO, а значит, вырождения полупроводника $\mathrm{CuI}$ не происходило. Однако в образцах FTO/ZnO/CuI, толщины CuI которых составляли 1.5 мкм (40 циклов SILAR), иодирование приводило к заметному коричневому окрашиванию образцов. Это окрашивание не было связано со следами $\mathrm{I}_{2}$ на поверхности CuI, так как его не удавалось устранить ни повторной тщательной промывкой образцов, ни их термообработкой на воздухе при $70^{\circ} \mathrm{C}$ в течение часа. Дополнительные опыты по иодированию не содержавших $\mathrm{CuI}$ образцов $\mathrm{FTO} / \mathrm{ZnO}$ также не выявили их окрашивания. По нашему мнению, коричневое окрашивание может быть объяснено избыточным иодированием пленок $\mathrm{CuI}$, которое осуществлялось через их поверхность, как раз вследствие высокой развитости этой поверхности, особенно в случаях, когда $\mathrm{CuI}$ осажден на наноструктурированные массивы ZnO. Огромная удельная поверхность изготовленных нами методом SILAR наноструктурированных пленок CuI подтверждается данными оптических исследований: пленки $\mathrm{CuI}$ преимущественно диффузно отражают и сильно рассеивают видимый свет. Эффект избыточного иодирования усиливается с ростом толщины $\mathrm{CuI}$ до 1.5 мкм, вероятно, вследствие увеличения развитости поверхности пленок. Подобное изменение морфологии поверхности $\mathrm{CuI}$ по мере увеличения числа циклов SILAR детально описано авторами [26]. Согласно $[44,46]$, при избыточном содержании иода в $\mathrm{CuI}$, в дополнение к вакансиям меди $V_{\mathrm{Cu}}$ возникают мелкие акцепторные уровни в виде антиструктурных дефектов $\mathrm{I}_{\mathrm{Cu}}$ и межузельного иода $\mathrm{I}_{i}$. Как указывается в [47], акцепторные уровни при увеличении их количества размываются в примесную зону, которая сливается с валентной зоной и образует единую зону вырожденного полупроводника. Верхняя граница этой зоны перемещается вверх, последний занятый уровень является уровнем Ферми. Таким образом, согласно [47], размытие примесной зоны приводит к еще одному важному следствию - к уменьшению ширины запрещенной зоны 
вырожденного полупроводника $p^{+}-\mathrm{CuI}$, что доказывается значением $E_{g} \approx 2.8$ эВ для $\mathrm{CuI}$ толщиной 1.5 мкм в образце $\mathrm{FTO} / \mathrm{ZnO} / \mathrm{CuI}$ после иодирования (рис. 5,d) и наблюдается визуально как коричневое окрашивание.

На рис. 6 показаны темновые вольт-амперные характеристики тестовых образцов $\mathrm{Cu} / \mathrm{FTO} / \mathrm{ZnO} / \mathrm{CuI} / \mathrm{Cu}$ c пленками $\mathrm{CuI}$, осажденными на поверхность электроосажденных наноструктурированных массивов $\mathrm{ZnO}$ за $n=30 \quad(a, b)$ и за $n=40 \quad(c)$ циклов SILAR при использовании в качестве анионного прекурсора водного раствора $0.025 \mathrm{M} \mathrm{NaI}$, до (a) и после $(b c)$ иодирования образцов $\mathrm{FTO} / \mathrm{ZnO} / \mathrm{CuI}$. $\mathrm{BAX}$, представленная на рис. 6, $a$, является типично диодной. Методика аналитической обработки темновой BAX и рассчитанные с ее помощью параметры этой барьерной гетероструктуры $n-\mathrm{ZnO} / p$-CuI подробно описаны нами в работе [27]. Как видно на рис. $6, b$, в результате иодирования образца $\mathrm{FTO} / \mathrm{ZnO} / \mathrm{CuI}$ с пленкой иодида меди толщиной 1 мкм величина шунтирующего сопротивления $R_{s h}$, умноженного на площадь контакта $S_{c}$, определяемая по обратной ветви статической ВАХ тестового образца $\mathrm{Cu} / \mathrm{FTO} / \mathrm{ZnO} / \mathrm{CuI} / \mathrm{Cu}$, снижается от $R_{s h} S_{c}=879$ Ом $\cdot \mathrm{cm}^{2}$ (рис. 6, $a$ ) до $R_{s h} S_{c}=188$ Ом $\cdot \mathrm{cm}^{2}$. Определяемое по прямой ветви темновой ВАХ последовательное сопротивление $R_{s h} S_{c}$ увеличивается, хотя и незначительно, от 8.5 до 9.0 Ом $\cdot \mathrm{cm}^{2}$. Коэффициент выпрямления диода $K$ снижается от 18 до 5, высота выпрямляющего барьера $p-n$-перехода $\Phi$ уменьшается от 1.1 до 1.0 эВ. Таким образом, в целом иодирование приводит к ухудшению электронных параметров диодной гетероструктуры $n-\mathrm{ZnO} / p$-CuI с пленкой иодида меди толщиной 1 мкм. Уменьшению коэффициента идеальности диода $\eta$ от 2.4 до 2.0 вследствие иодирования образца $\mathrm{FTO} / \mathrm{ZnO} / \mathrm{CuI}$ с пленкой иодида меди толщиной 1 мкм сопутствует изменение режимов переноса. Если до иодирования барьерной гетероструктуры при малых напряжениях прямого смещения $0<U<0.15 \mathrm{~B}$ имело место совместное влияние механизмов рекомбинации и туннельного переноса носителей заряда, а при увеличении напряжения свыше $0.15 \mathrm{~B}$ механизм переноса становился туннельно-рекомбинационным (рис. 6,a), то после иодирования рекомбинационный режим при $0.1<U<0.5 \mathrm{~B}$ сменялся диффузионным при $U>0.5 \mathrm{~B}$ (рис. $6, b$ ).

В соответствии с зарегистрированными нами изменениями структуры и оптических свойств в результате иодирования образца $\mathrm{FTO} / \mathrm{ZnO} / \mathrm{CuI}$ с пленкой иодида меди толщиной 1.5 мкм происходит формирование барьерной гетероструктуры $n-\mathrm{ZnO} / p^{+}$-CuI, которая демонстрирует показанную на рис. 6,c BAX обращенного диода. В этом случае за счет повышения потолка валентной зоны в $p^{+}$-CuI по сравнению с $p$-CuI при обратном смещении электроны из валентной зоны вырожденного полупроводника $p^{+}$-CuI туннелируют в зону проводимости $n$-ZnO. Изготовленная нами гетероструктура для обращенного диода при обратном смещения $U=-2.0 \mathrm{~B}$ имеет плотность тока туннелирования $47 \mathrm{MA} / \mathrm{cm}^{2}$ при комнатной температуре (рис. 6,c). При прямом смещении туннелирования в ней не происходит, поскольку перенос заряда через возникающий потенциальный барьер может осуществляться только за счет термоэлектронной эмиссии. Расчет коэффициента кривизны дает значение $\gamma=12 \mathrm{~B}^{-1}$, которое подтверждает добротность созданной нами гетероструктуры для обращенного диода $[10,12,13]$. Заметим, что многочисленные исследователи [16-18,21,44], которые изготавливали диодные гетероструктуры на основе оксида цинка и иодида меди, использовали гладкие и прозрачные пленки CuI, истинная площадь поверхности которых не настолько значительно превышала геометрическую площадь поверхности, как это происходило в нашем случае, и поэтому до сих пор в литературе не было описано коричневое окрашивание образцов этих гетероструктур вследствие избыточного иодирования $\mathrm{CuI}$, а также не были представлены BAX обращенных диодов на их основе.

\section{4. Заключение}

Проведено исследование влияния режимов осаждения методом SILAR и последующего иодирования пленок $\mathrm{CuI}$ на гладких подложках из стекла, слюды и FTO, а также на поверхности электроосажденных наноструктурированных массивов оксида цинка, на их структуру, электрические и оптические свойства. Выявлена связь изменений, наблюдаемых в структуре и свойствах этого материала, с имеющимися в нем изначально и создаваемыми в процессе иодирования точечными дефектами. Обнаружено, что причиной и условием формирования гетероструктуры обращенного диода на основе электроосажденного в импульсном режиме наномассива оксида цинка и изготовленной методом SILAR пленки иодида меди является формирование вырожденного полупроводника $p^{+}-\mathrm{CuI}$ путем избыточного иодирования слоев этого наноструктурированного материала через его развитую поверхность. Впервые изготовлена барьерная гетероструктура $n-\mathrm{ZnO} / p^{+}$-CuI с вольт-амперной характеристикой обращенного диода, коэффициент кривизны которой $\gamma=12 \mathrm{~B}^{-1}$, подтверждает ее добротность и перспективность использования в качестве основы новой конструкции обращенного диода.

\section{Список литературы}

[1] Microelectronics to nanoelectronics: materials, devices \& manufacturability, ed. by A.B. Kaul (U.S., CRC Press, Tailor \& Francis Group, N.Y., 2012).

[2] M. Lundstrom, J. Guo. Nanoscale transistors - Device physics, modeling and simulation (Springer com., 2006).

[3] M. Salimian, M. Ivanov, F.L. Deepak, D.Y. Petrovykh, I. Bdikin, M. Ferro, A. Kholkin, E. Titusa, G. Goncalves. J. Mater. Chem. C, 3, 11516 (2015).

[4] Q.-Q. Sun, Y.-J. Li, J.-L. He, W. Yang, P. Zhou, H.-L. Lu, S.-J. Ding, D.W. Zhang. Appl. Phys. Lett., 102, 093104 (2013).

[5] H. Okumura, D. Martin, M. Malinverni, N. Grandjean. Appl. Phys. Lett. 108, 072102 (2016). 
[6] K. Zhang, H. Liang, Y. Liu, R. Shen, W. Guo, D. Wang, X. Xia, P. Tao, C. Yang, Y. Luo, G. Du. Scientific Rep., 4, 6322 (2014).

[7] V.K. Khanna. Integrated nanoelectronics: nanoscale CMOS, post-CMOS and allied nanotechnologies (India, Springer Nature, 2016).

[8] D. Kälblein, R.T. Weitz, H.J. Böttcher, F. Ante, U. Zschieschang, K. Kern, H. Klauk. Nano Lett., 11, 5309 (2011).

[9] K. Gadani, D. Dhruv, Z. Joshi, H. Boricha, K.N. Rathod, M.J. Keshvani, N.A. Shah, P.S. Solanki. Phys. Chem. Chem. Phys., 18, 17740 (2016).

[10] Z. Zhang, R. Rajavel, P. Deelman, P. Fay. IEEE Microwave Wireless Components Lett., 21 (5), 267 (2011).

[11] S.M. Sze, K.K. Ng. Physics of semiconductor devices. 3rd edn (U.S., John Wiley \& Sons, Inc., 2007).

[12] К.С. Ржевкин. Физические принцииы действия полупроводниковых приборов (М., Изд-во МГУ, 1986).

[13] S. Agarwal, E. Yablonovitch. IEEE Trans. Electron Dev., 61 (5), 1488 (2014).

[14] Z. Yang, M. Wang, J. Ding, Z. Sun, L. Li, J. Huang, J. Liu, J. Shao. ACS Appl. Mater. Interfaces, 7 (38), 21235 (2015).

[15] S.M. Hatch, J. Briscoe, S. Dunn. Adv. Mater., 25, 867 (2013).

[16] K. Ding, Q.C. Hu, D.G. Chen, Q.H. Zheng, X.G. Xue, F. Huang. IEEE Electron Dev. Lett., 33 (12), 1750 (2012).

[17] F.-L. Schein, H. Wenckstern, M. Grundmann. Appl. Phys. Lett., 102, 092109 (2013).

[18] C. Yang, M. Kneiß, F.-L. Schein, M. Lorenz, M. Grundmann. Scientific Rep., 6, 21937 (2016).

[19] C. Xiong, R. Yao. Optik, 126, 1951 (2015).

[20] Transparent electronics: from synthesis to applications, ed. by A. Facchetti, T.J. Marks (United Kingdom, John Wiley \& Sons, Ltd., 2010).

[21] C. Liu, M. Peng, A. Yu, J. Liu, M. Song, Y. Zhang, J. Zhai. Nano Energy, 26, 417 (2016).

[22] Z. Yang, M. Wang, S. Shukla, Y. Zhu, J. Deng, H. Ge, X.Wang, Q. Xiong. Sci Rep., 5, 11377 (2015).

[23] B.R. Sankapal, E. Goncalves, A. Ennaoui, M.C. Lux-Steiner. Thin Sol. Films, 451-452, 128 (2004).

[24] R.N. Bulakhe, N.M. Shinde, R.D. Thorat, S.S. Nikam, C.D. Lokhande. Current Appl. Phys., 13, 1661 (2013).

[25] B.R. Sankapal, A. Ennaoui, T. Guminskaya, T. Dittrich, W. Bohne, J. Rfhrich, E. Strub, M.C. Lux-Steiner. Thin Sol. Films, 480-481, 142 (2005).

[26] S.L. Dhere, S.S. Latthe, C. Kappenstein, S.K. Mukherjee, A.V. Rao. Appl. Surf. Sci., 256, 3967 (2010).

[27] Н.П. Клочко, В.Р. Копач, Г.С. Хрипунов, В.Е. Корсун, Н.Д. Волкова, В.Н. Любов, М.В. Кириченко, А.В. Копач, Д.О. Жадан, А.Н. Отченашко. ФТП, 51 (6), 821 (2017).

[28] N. Yamada, R. Ino, Y. Ninomiya. Chem. Mater., 28 (14), 4971 (2016).

[29] Z. Liu, Y. Pei, H. Geng, J. Zhou, X. Meng, W. Cai, W. Liu, J. Sui. Nano Energy, 13, 554 (2015).

[30] Q. Yang, C. Hu, S. Wang, Y. Xi, K. Zhang. J. Phys. Chem. C, 117, 5515 (2013).

[31] N. Chahmat, A. Haddad, A. Ain-Souya, R. Ganfoudi, N. Attaf, M.S. Aida, M. Ghers. J. Modern Phys., 3, 1781 (2012).

[32] R.R. Ahire, B.R. Sankapal, C.D. Lokhande. Mater. Res. Bulletin, 36, 199 (2001).

[33] Н.П. Клочко, Г.С. Хрипунов, Ю.А. Мягченко, Е.Е. Мельничук, В.Р. Копач, Е.С. Клепикова, В.Н. Любов, А.В. Копач. ФТП, 48 (4), 549 (2014).
[34] Н.П. Клочко, Е.С. Клепикова, Г.С. Хрипунов, Н.Д. Волкова, В.Р. Копач, В.Н. Любов, М.В. Кириченко, А.В. Копач. ФТП, 49 (2), 219 (2015).

[35] N.P. Klochko, K.S. Klepikova, I.I. Tyukhov, Y.O. Myagchenko, E.E. Melnychuk, V.R. Kopach, G.S. Khrypunov, V.M. Lyubov, A.V. Kopach, V.V. Starikov, M.V. Kirichenko. Solar Energy, 117, 1 (2015).

[36] N.P. Klochko, K.S. Klepikova, I.I. Tyukhov, Y.O. Myagchenko, E.E. Melnychuk, V.R. Kopach, G.S. Khrypunov, V.M. Lyubov, A.V. Kopach. Solar Energy, 120, 330 (2015).

[37] Н.П. Клочко, Е.С. Клепикова, В.Р. Копач, Г.С. Хрипунов, Ю.А. Мягченко, Е.Е. Мельничук, В.Н. Любов, А.В. Копач. ФТП, 50 (3), 357 (2016).

[37] D.K. Schroder. Semiconductor material and device characterization. 3rd edn (N.Y., John Wiley \& Sons, Inc., 2006).

[38] T. Prasada Rao, M.C. Santhoshkumar. Appl. Surf. Sci., 255, 4579 (2009).

[39] A. Axelevitch, G. Golan. Facta Universitatis. Ser.: Electron. Energetics, 26 (3), 187 (2013).

[40] V.R. Kopach, K.S. Klepikova, N.P. Klochko, I.I. Tyukhov, G.S. Khrypunov, V.E. Korsun, V.M. Lyubov, A.V. Kopach, R.V. Zaitsev, M.V. Kirichenko. Solar Energy, 136, 23 (2016).

[41] В.Р. Копач, Е.С. Клепикова, Н.П. Клочко, Г.С. Хрипунов, В.Е. Корсун, В.Н. Любов, М.В. Кириченко, А.В. Копач. ФТП, 51 (3), 348 (2017).

[42] Zinc oxide materials for electronic and optoelectronic device applications, ed. by C.W. Litton, D.C. Reynolds, T.C. Collins (United Kingdom, John Wiley \& Sons, Ltd., 2011).

[43] H. Morkoç, Ü. Özgür. Zinc Oxide: Fundamentals, Materials and Device Technology (Weinheim, Wiley-VCH Verlag $\mathrm{GmbH} \&$ Co. KGaA, 2009).

[44] M. Grundmann, F.-L. Schein, M. Lorenz, T. Böntgen, J. Lenzner, H. Wenckstern. Phys. Status Solidi A, 210, 1671 (2013).

[45] C. Yang, M. Kneiß, M. Lorenz, M. Grundmann. Proc. Natl. Acad. Sci. USA, 113, 12929 (2016).

[46] J. Wang, J. Li, S.-S. Li. J. Appl. Phys., 110, 054907 (2011).

[47] Г.И. Епифанов. Физические основы микроэлектроники (М., Сов. радио, 1971).

[48] К.В. Шалимова. Физика полупроводников (М., Энергоатомиздат, 1985).

[49] Y. Wang, H.-B. Fang, R.-Q. Ye, Y.-Z. Zheng, N. Li, X. Tao. RSC Adv., 6, 24430 (2016).

Редактор Г.А. Оганесян 


\title{
Heterostructure for a backward diode based on the electrodeposited in a pulsed mode zinc oxide nanoarray and copper iodide film made by SILAR
}

N.P. Klochko, V.R. Kopach, G.S. Khrypunov,

V.E. Korsun, V.M. Lyubov, D.O. Zhadan,

A.N. Otchenashko, M.V. Kirichenko, M.G. Khrypunov

National Technical University

„Kharkiv Polytechnic Institute“, 61000 Kharkiv, Ukraine

\begin{abstract}
A heterostructure based on the array of zinc oxide nanorods and on the nanostructured copper iodide film was formed as a basis of the perspective design of the backward diode. The effect of the SILAR deposition regimes and subsequent iodization of $\mathrm{CuI}$ films on smooth glass, mica and FTO substrates, as well as on the surface of the electrodeposited nanostructured zinc oxide arrays, on their structure, electrical and optical properties was studied. The relationship of the changes observed in the structure and properties of this material with the point defects inherent in it and created in the process of iodination is revealed. It was found that the cause and condition for the formation of the backward diode heterostructure based on the electrodeposited pulsed zinc oxide nanoarray and the SILAR deposited copper iodide film is the formation of a degenerate $p^{+}$-CuI semiconductor by excess iodization of the layers of this nanostructured material through its developed surface. For the first time, the barrier $n-\mathrm{ZnO} / p^{+}-\mathrm{CuI}$ heterostructure was created with the current-voltage characteristic of the backward diode with $\gamma=12 \mathrm{~V}^{-1}$ curvature, that confirms its quality factor.
\end{abstract}

